\title{
BMJ Open Rethinking exercise identity: a qualitative study of physically inactive cancer patients' transforming process while undergoing chemotherapy
}

\author{
Lis Adamsen, ${ }^{1,2}$ Christina Andersen, ${ }^{1}$ Christian Lillelund, ${ }^{1}$ Kira Bloomquist, ${ }^{1}$ \\ Tom Møller ${ }^{1,2}$
}

To cite: Adamsen L, Andersen C, Lillelund C, et al. Rethinking exercise identity: a qualitative study of physically inactive cancer patients' transforming process while undergoing chemotherapy. BMJ Open 2017;7:e016689. doi:10.1136/ bmjopen-2017-016689

- Prepublication history and additional material for this paper are available online. To view please visit the journal online (http://dx.doi.org/10.1136/ bmjopen-2017-016689).

Received 2 March 2017 Revised 27 May 2017 Accepted 5 July 2017

CrossMark

${ }^{1}$ The University Hospitals Centre for Health Research, UCSF Copenhagen University Hospital Rigshospitalet, Department 9701, Copenhagen, Denmark ${ }^{2}$ Department of Public Health, Faculty of Health and Medical Sciences, University of Copenhagen, Copenhagen, Denmark

Correspondence to professor Lis Adamsen; la@ucsf.dk

\section{ABSTRACT}

Objective To explore physically inactive breast and colon cancer patients' prediagnosis exercise history and attitudes to physical activity (PA) and experiences in initiating PA while undergoing adjuvant chemotherapy. Design An explorative qualitative study guided the interpretive analysis of semistructured, open-ended interviews conducted at initiation of chemotherapy and after 12 weeks. The study was embedded in a pilot randomised controlled trial.

Setting Participants were recruited from the Oncological Department at a hospital in Copenhagen, Denmark.

Participants 33 patients with cancer, median age 49 years: 25 patients with breast cancer and 8 with colon cancer, $72 \%$ with a low cardiac respiratory fitness level and the majority with a high level of education. Patients received adjuvant chemotherapy, oncologist's PA recommendation and exercise, cancer nurse specialist's counselling prior to allocation to PA interventions or waitlist control group.

Results Prediagnosis exercise had been excluded from patients' daily lives due to perceptions of exercise as boring, lack of discipline and stressful work conditions for both genders. Recommendations from oncologists and nurses inspired the patients to reconsider their attitudes and behaviour by accepting recruitment and participation in PA interventions during chemotherapy. Despite extensive side effects, most patients adhered to their PA commitment due to their perception of the bodily, emotional and social benefits and support of healthcare professionals, peers and family.

Conclusion The patients' attitude towards exercise transformed from having no priority in patients' daily lives prediagnosis to being highly prioritised. This study identified four important phases in the exercise transformation process during the patients' treatment trajectory of relevance to clinicians in identifying, motivating and supporting physically inactive patients with cancer at long-term risk. Clinicians should address young, highly educated patients with cancer at onset of adjuvant chemotherapy due to their specific risk of a sedentary lifestyle resulting from being in stressful, ambitious careers.

Trial registration number Current Controlled Trials (ISRCTN24901641), Stage: Qualitative results.
Strengths and limitations of this study

- Understanding the transformation of behaviour among physically inactive patients with cancer is crucial to developing effective patient-clinician collaborative strategies to reduce comorbidities and minimise cancer recurrence. To address this issue, we performed a qualitative study involving in-depth, pre and post semistructured interviews with 33 patients with cancer who were physically inactive prior to their diagnosis.

- This qualitative study incorporated exclusively physically inactive patients with cancer by means of a systematic screening procedure based on national guidelines conducted in the oncology clinic.

- The study is limited by not incorporating patients who declined to participate in physical activity interventions.

- The study revealed ethical challenges and dilemmas associated with randomised controlled trial designs aimed at prediagnosis, physically inactive patients when they were not randomly allocated to their preferred type of exercise.

\section{INTRODUCTION}

Breast and colon cancers are two of the most common cancers in the West, the former representing $27 \%$ and the latter $8 \%$ of new cancer incidence in Denmark annually. ${ }^{1}$ Reviews and meta-analyses document that exercise and physical activity (exercise/PA) interventions for patients with cancer following treatment beneficially affect physical, psychological and quality of life parameters, ${ }^{2} 3$ whereas the evidence during adjuvant breast cancer therapy is promising but inconclusive. ${ }^{4} 5$ Several observational studies have shown that regular PA among breast and colon cancer patients may reduce the incidence and risk of cancer recurrence. ${ }^{6-8}$ However, a European survey among cancer survivors revealed that less than $25 \%$ met current PA guidelines $^{9}$; therefore physically inactive patients 
with cancer with negative prediagnostic exercise history represent a specific risk population in terms of survival, cardiovascular disease and diabetes. ${ }^{10-12}$

The majority of breast and colon cancer patients receiving chemotherapy face a variety of symptoms and side effects, including fatigue, pain, anxiety and depression, putting them at risk of further physical, functional and emotional decline during treatment. ${ }^{12-14}$ Additionally, the literature shows that colon or breast cancer patients undergoing chemotherapy experience a $50 \%$ decline in PA compared with prediagnosis. ${ }^{15} 16$

To encourage physically inactive patients with cancer not meeting national guidelines $(150 \mathrm{~min} /$ week regular, moderate PA and $2 \times 20 \mathrm{~min} /$ week strenuous exercise ${ }^{17}{ }^{18}$ ) to initiate and increase PA, exploring their perceptions of the recruitment process and perspectives on participation in interventions is essential. However, PA interventions targeted prediagnosis physically inactive patients with cancer are inadequate and understudied. ${ }^{19} 20$

Consequently, recruitment must be designed to identify and motivate prediagnosis physically inactive patients with cancer to participate in PA interventions. No studies have qualitatively explored whether oncologist recommendations for PA, combined with counselling by an exercise cancer nurse specialist (ECNS) at onset of chemotherapy, can positively impact PA among such patients undergoing chemotherapy, specifically patients perceiving themselves as non-exercisers.

A few studies have qualitatively examined breast and colon cancer patients' participation in exercise interventions during/after treatment, though without focusing and differentiating between the patients' prediagnosis PA and exercise history. ${ }^{21-27}$

The aim of this study was to explore physically inactive breast and colon cancer patients' prediagnosis exercise history, attitudes to and experiences in initiating physical activity while undergoing adjuvant chemotherapy.

\section{METHODS}

\section{Study design}

The study employed an explorative qualitative approach, based on pre and post open-ended semistructured interviews and incorporated principles derived from interpretive phenomenological analysis (IPA). ${ }^{28}$ The consolidated criteria for reporting qualitative research checklist was used. ${ }^{29}$

\section{Ethics}

Ethical approval was obtained for the present interview study and feasibility $\mathrm{RCT}^{30}$ in a combined application and approval obtained from the Scientific Committee of the Capital Region of Denmark ${ }^{30}$ (file no H-1-2011-131) and the Danish Data Protection Agency (file no 2011-416349).

The present interview study did not include participants who declined participation in the intervention study, which is in accordance with Danish biomedical ethics legislation.

\section{Participants and recruitment}

The interview study incorporated patients from two outpatient oncology clinics and was embedded in a randomised controlled pilot study on physically inactive breast and colon cancer patients who: (1) shared a similar PA risk profile, (2) underwent radical surgery and were referred to adjuvant chemotherapy and (3) for whom early initiated, systematic recommendations and screening procedures for PA could be tested/integrated into daily clinical practice, see Recruitment procedure section.

Figure 1, which provides an overview of recruitment, study period and qualitative interviews, illustrates the similarities between the treatment trajectories (surgery and referred to adjuvant chemotherapy), interventions and allocation to interview study of the two diagnostic groups. ${ }^{30} 31$

\section{Recruitment procedure}

Recruitment procedure include (1) at the initial chemotherapy consultation and based on evidence, the oncologist recommended that patients be physically active during treatment; (2) the oncology nurse subsequently screened patients concerning prediagnosis PA over the last 3 months using questions based on national physical activity guidelines ${ }^{18}$ : "Did you perform less than

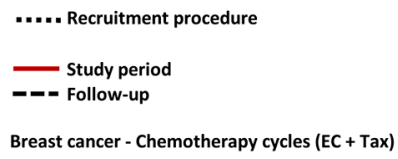

Colon cancer - Chemotherapy cycles (FOLFOX)

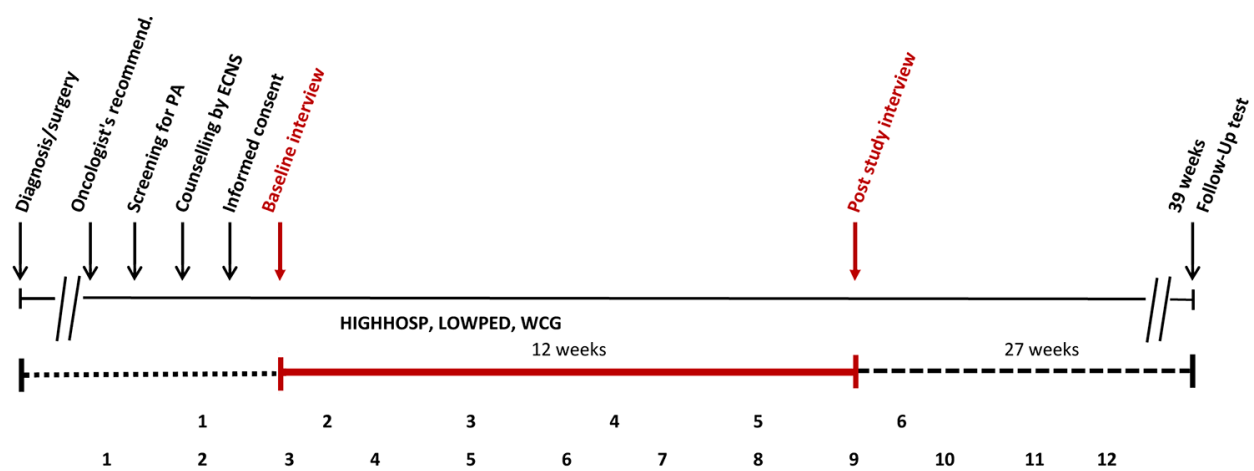

Figure 1 Overview of recruitment, study period and qualitative interviews. ECNS, exercise cancer nurse specialist; FOLFOX, oxaliplatin, 5-flourouracil and folinic acid; PA, physical activity; WCG, waitlist control group 
150 min of moderate physical activity per week?" and "Did you perform less than $2 \times 20$ min of strenuous leisure time physical activity per week?". Examples of moderate/ strenuous PA were given to the patients. Patients who replied affirmatively were eligible and (3) on initiation of chemotherapy the ECNS informed eligible patients verbally and in writing about the PA interventions and the interview study before obtaining informed written consent.

\section{PA interventions and waitlist control}

In addition to the oncologist PA recommendations, the patients received 1 hour of face-to-face counselling from the ECNS in health promotion and exercise, with feedback on physiological tests at baseline, weeks 6 and 12 and counselling on management of symptoms/side effects.

Patients were included in one of the following PA interventions or waitlist control for 12 weeks: (1) a hospital-based, supervised, high-intensity group exercise intervention (cardiovascular, heavy resistance training, relaxation and body awareness training, massage; 9 hours / week) (HIGHHOSP); (2) a home-based, low-intensity individual pedometer intervention (10000 steps/day) (LOWPED); or (3) a waitlist control group (WCG). WCG patients had no restrictions on PA during the 12-week study period, in accordance with Danish ethics guidelines. Patients received standard medical care regardless of allocation. ${ }^{31}$ Following the 12-week study period, the LOWPED and WCG participants were allowed to participate in the HIGHHOSP intervention.

\section{Sampling and semistructured qualitative interviews}

After receiving ethical approval, a purposive sample was obtained based on the following criteria: age $>18$ years, breast or colon cancer diagnosis, adjuvant chemotherapy, PA below national guidelines and group allocation.

The feasibility and interview study established an opportunity to gain profound insight into the phenomenon of physical inactivity and initiating behavioural change during adjuvant chemotherapy. Accordingly, the number of patients to be interviewed (sample size) was not decided in advance of this study. Following interviews at baseline and after a 12-week study period (HIGHHOSP $n=12$, LOWPED $n=12$, WCG $n=9$ ), responses to the interview guide themes proved to be repetitive and redundant, with no new essential information surfacing.

A researcher (LA, not involved in the interventions) interviewed patients individually, face-to-face, in an office close to the clinic. The interview method gathered patient feedback on; exercise history, the oncologist/exercise cancer nurse specialist's information/counselling in the clinic, preferences and perception of participation in PA intervention, reasons for adherence/non-adherence to PA and supportive components for PA maintenance. Each interview lasted 45-90 min and were digitally recorded and transcribed verbatim (see online supplementary file $1)$.

\section{Analysis}

The interviews were reidentified and qualitative data subject to IPA, ${ }^{28}$ which is a flexible analytic approach that applies descriptive to interpretive processes in a non-mandatory four-step method for cross-case thematic analysis of qualitative data.

In step 1, the first author initially read and reread the transcripts to gain a comprehensive impression of preliminary themes. In step 2, the 33 baseline interview transcripts and the 33 12-week, poststudy interview transcripts were organised into initial notes and coding by sorting the text into meaning units identifying preliminary themes. Selected quotations and contextual and conceptual annotations were noted during identification of the motivational, physical, emotional and social constraints and promoters for exercise integration. Three researchers (LA, TM, CA) conducted triangulation to minimise intraobserver bias using these initial steps of decontexualisation and recontextualisation especially with regard to connecting and substantially extracting the essence of notes and codes into code groups (eg, prediagnosis exercise history, oncologists' recommendation). The respective code groups and emergent themes identified were only included in so far as the researchers (LA, $\mathrm{CA}, \mathrm{TM})$ were in agreement that the interview material (quotations) verified sufficient data saturation, indicating that the emergent themes are highly saturated.

Accordingly, in step 3, we identified emergent major themes based on coding and the contextual and conceptual annotations. At this point, the role of interventions, WCG and health professionals and psychosocial support from peers and relatives was specifically explored to clarify the underlying mechanisms behind patient experiences during the 12-week period. The last step 4 involved merging and synthesising the cross-case findings into a unifying model of an exercise behaviour transformation model based on the chronological appearance of major themes as they emerged during the treatment trajectory and evolved in the participants' experiences. Table 1 provides an overview of the IPA analytical process.

\section{RESULTS}

Table 2 describes the patient demographics and medical characteristics $(n=33)$. A majority of the patients were relatively young (median age 49 years) with a high educational level (breast cancer $n=25$, colon cancer $n=8$ ). All patients received adjuvant chemotherapy during the study period. Seventy-two per cent presented low or very low cardiorespiratory fitness. Intervention adherence rate was $74 \%$ for HIGHHOSP and $75 \%$ for LOWPED.

\section{Looking back: exercise not prioritised in daily life}

In the 12 months prior to diagnosis, none of the patients had integrated or prioritised exercise in their daily lives. A lack of self-discipline, desire, motivation, physical laziness and a stressful work life were a common feature in patient narratives, regardless of gender and diagnosis. 
Table 1 Overview of the interpretative phenomenological analysis process

Step 1: $\quad$ Participants' life experiences with exercise, the influence of the cancer diagnosis, the meeting with

Comprehensive clinicians and receiving antineoplastic treatment, initiating exercise.

impression of

preliminary themes

\section{Step 2:}

Selective code groups and quotations

\section{Exercise history}

Never active; I never

did sports when I was child.

Exercise has never appealed to me - I think it's boring. On and Off; $M y$ exercise habits have always varied. ... my work takes up a lot of space.

Active prediagnosis;

Stress, family obligations and stomach problems changed my life. I was inactive in the months prior to getting colon cancer

\section{Timing}

My first consultation

with the oncologist was motivating and optimistic and I wanted to start exercising.

For me, it was perfect timing

Motivation

The powerlessness I felt against cancer was the most crucial factor in reconsidering my way of life. Being told by the doctor and cancer nurse specialist ... that doing exercise could perhaps mean that l'd feel better. Preference really needed to get into forcing the disease Prot into forcing the disease and the high intensity group. I chemotherapy to fade into needed a boost to begin the background. an exercise programme. They [peers] texted me I was disappointed about when I was bedridden. being assigned to WCG. My husband and friends got involved $100 \%$. The coaches were great at cracking the whip. and side-effects

I couldn't participate for four days after l'd received Taxotere. ...

My joints ached. ...

Physical, emotional and social benefits of PA

The days that I exercise...

Barriers in PA - symptom Self-discipline I'm feeling the worst, I only I feel strong enough to walk 100-300 steps from work on my terms. my bed. ... PA goals

effects become secondary. I want to continue being The pedometer affects my physically active at a mood.... training club for elderly people.

Stressful work I spoke with my employer about how stressful work was. I'm convinced that I'll resign if things don't change, so I have time to work out.

Now I have fewer responsibilities and will start part-time. My illness has made me see what is important. ... My disease has led me to reconsider my work situation. I have to take better care of myself.

\begin{tabular}{|c|c|c|c|c|}
\hline $\begin{array}{l}\text { Step 3: } \\
\text { Emergent } \\
\text { chronological major } \\
\text { themes }\end{array}$ & $\begin{array}{l}\text { Looking back: } \\
\text { Exercise not } \\
\text { prioritised in daily life }\end{array}$ & $\begin{array}{l}\text { Transforming attitudes, } \\
\text { oncologists put exercise } \\
\text { on the agenda }\end{array}$ & $\begin{array}{l}\text { Breaks during } \\
\text { chemotherapy: Quickly } \\
\text { back on track }\end{array}$ & $\begin{array}{l}\text { Rethinking exercise } \\
\text { identity and } \\
\text { transforming priorities }\end{array}$ \\
\hline
\end{tabular}

PA, physical activity; WCG, waitlist control group.

Patient narratives comprised three typologies: (1) 'Never active', desire to exercise lacking since childhood; (2) 'On and off', desire to exercise fluctuates; multiple attempts to begin but no adherence; and (3) 'Active prediagnosis', stopped exercising due to work-related stress and symptom load. Type 1 patients emphasised that they had never participated in sports. Patient 23: "Exercise has never appealed to me - I think it's boring. I never did sports when I was child. I have the time but not the desire" (female, 42, breast cancer). Patient 16: "My exercise habits have been virtually non-existent the last five years. I'm a civil engineer and construction manager with tough deadlines. I could've found the time but I'm too lazy" (Female, 38, breast cancer). Type 2 patients described short intense periods of exercise, followed by a loss of desire lasting up to a year before resuming exercise. Patient 26: "My exercise habits have always varied. In the last twoyears I haven't exercised at all. My work takes up a lot of space. I've neglected myself. I lack discipline" (female, 49, breast cancer). Patients with colon cancer 
Table 2 Demographic and medical characteristics of study population $(n=33)$

\begin{tabular}{|c|c|}
\hline & Total $n=33$ \\
\hline Gender: female/male & $28 / 5$ \\
\hline Age, median (range) & $49(31-73)$ \\
\hline \multicolumn{2}{|l|}{ Diagnosis } \\
\hline Breast/colon & $25 / 8$ \\
\hline $\begin{array}{l}\text { Study group allocation (HIGHHOSP/LOW } \\
\text { PED/CONTROL) }\end{array}$ & $12 / 12 / 9$ \\
\hline $\begin{array}{l}\text { Intervention adherence (HIGHHOSP/LOW } \\
\text { PED), \% }\end{array}$ & $74 / 75$ \\
\hline Mastectomy/lumpectomy & $11 / 14$ \\
\hline Ostomy & 4 \\
\hline \multicolumn{2}{|l|}{ Chemotherapy regimen } \\
\hline Breast standard adjuvant & 19 \\
\hline Breast READ protocol adjuvant & 6 \\
\hline Colon FOLFOX adjuvant & 8 \\
\hline \multicolumn{2}{|l|}{ Educational level } \\
\hline Lower & 4 \\
\hline Secondary & 8 \\
\hline Advanced & 21 \\
\hline \multicolumn{2}{|l|}{ Cardiorespiratory fitness at baseline ${ }^{*}$} \\
\hline Very low or low, n (\%) & $24(72)$ \\
\hline Medium & $8(24)$ \\
\hline High & $1(4)$ \\
\hline \multicolumn{2}{|l|}{ Cardiorespiratory fitness $\left(\mathrm{VO}_{2}\right.$ peak) } \\
\hline 12 weeks/baseline ratio & 0.90 \\
\hline 39 weeks/baseline ratio & 1.05 \\
\hline Weight, mean (SD) & 70.7 (10.5) \\
\hline BMI, mean (SD) & $24.0(3.7)$ \\
\hline \multicolumn{2}{|l|}{ Marital status } \\
\hline Married/living with partner & 23 \\
\hline Single/divorced/widowed & 10 \\
\hline \multicolumn{2}{|l|}{ Smoking status } \\
\hline Never/past $†$ & $10 / 16$ \\
\hline Current & 7 \\
\hline Alcohol intake/week, mean (SD) & $4.7(4.9)$ \\
\hline
\end{tabular}

*Age adjusted and compared with Scandinavian background population.

†Cessation $>1$ year.

$\mathrm{BMI}$, body mass index; breast READ protocol adjuvant, six series of docetaxel plus cyclophosphamide; breast standard adjuvant, three series of epirubicin and cyclophosphamide followed by three series of docetaxel; colon FOLFOX adjuvant, oxaliplatin, 5-flourouracil and folinic acid; n, no of participants.

stressed that abdominal pain 6-12 months prior to diagnosis reduced their desire to exercise. Patient 14: "Two years ago I went to spinning and strength training. Then I had too many work deadlines ... Stress, family obligations and stomach problems changed my life so I was inactive in the months prior to getting colon cancer" (male, 38, colon cancer).

Various patients had primarily spent their leisure time on their careers, marginalising other activities. Patient 33: "I'm 33, have an MSc and head a team of 25 employees. We have tough deadlines and I feel a huge sense of responsibility. Three years ago I ran, biked and swam about seven hours weekly, but work prevented that" (male, 33, colon cancer).

Especially young, educated people reported high stress, considerable work pressure and tight deadlines prior to the appearance of symptoms.

\section{Transforming attitudes, oncologists put PA/exercise on the agenda}

None of the patients had initiated PA after being diagnosed or prior to their first consultation with the oncologist, when PA during chemotherapy was advised. Patient 28: "My first consultation with the oncologist was motivating and optimistic and I wanted to start exercising" (female, 46, breast cancer). Patient 26: "The oncologist's recommendation improved my mood. For me, it was perfect timing" (female, 49, breast cancer). Patients said they felt well informed. Patient 23: "Thinking about having side effects from chemo for five months was horrible, but it was great that the oncologist informed me about being physically active during chemotherapy. I needed support from professionals to feel safe" (female, 43, breast cancer).

The first consultation was followed by a dialogue with an ECNS, who described the barriers, benefits and safety aspects of PA in detail. Patient 14: "The powerlessness I felt against cancer was the most crucial factor in reconsidering my way of life... Being told by the doctor and cancer nurse specialist ... that doing exercise could perhaps mean that I'd feel better, that I could do something on my own" (male, 38, colon cancer). The patients felt that it was a suitable opportunity to focus on their lifestyle and PA when they had to undergo chemotherapy.

After allocation to interventions or WCG, patients were asked about their PA preference. The majority preferred HIGHHOSP with peers with supervision by a sports' physiologist and nurse, which they assumed would strengthen their participation. Patients not allocated to their preference expressed disappointment. Patient 27: "I really needed to get into the high-intensity group due to my non-existent discipline. I needed a boost to begin an exercise programme. I felt disappointed when I was assigned to the wait-list control group" (female, 44, breast cancer).

WCG quotes show that two-thirds of these patients initiated PA during the 12-week study period. Patient 26: "I was disappointed about being assigned to WCG, but my husband and I decided to weight train three times weekly at our fitness centre" (female, 49, breast cancer).

\section{Breaks during chemotherapy: quickly back on track}

Side effects of chemotherapy were overwhelming and patients were out of commission for days. Breast cancer patients' mentioned fatigue, infections and achy joints 
and muscles. Patient 5: "My joints ached. ... I couldn't sleep because my hips, lower back and legs hurt. The side effects didn't worsen due to hard exercise" (female, 54 , breast cancer). One patient with colon cancer experienced the impact of exercise on his physical capacity. "The days that I exercise ... I would initially think to myself - oh, the next two hours are going to be tough... But when I'm done ... I feel great and my side effects become secondary" (male, 70, colon cancer).

However, the majority of patients took 3-5 day breaks after chemotherapy before resuming exercise.

Patient 10: 'I couldn't participate for four days after I'd received Taxotere. It was horrible. I was burning up inside. I made friends with the others in my exercise group and they texted me when I was bedridden. I overcame what was happening, resumed exercising ... We toughened up, forcing the disease and chemotherapy to fade into the background" (female, 44, breast cancer).

Supervised patients reported emotional and social benefits of being with others facing similar circumstances; the coaches and camaraderie helped in maintaining participation despite side effects. Patient 4: "The coaches were great at cracking the whip. I really enjoyed playing ball in groups; it put me in a good mood because we competed to score the highest" (female, 38, breast cancer).

Pedometer patients also experienced emotional and social benefits. Patient 14: "I still had the desire, but my body said no. ... So just after chemo, when I'm feeling the worst, I only walk 100-300 steps from my bed to the kitchen ... The pedometer affects my mood. I end up walking and getting started again" (male, 38, colon cancer). Family and friends becoming involved in PA was important. Patient 99: "My husband and friends got involved $100 \%$. My husband researched all possible walking routes. There was a goal -10000 steps. So we did it" (female, 59, breast cancer).

While the majority of patients needed to take breaks after chemotherapy, they adhered to their commitments to PA. Six patients, however, failed to realise their ambitions when the side effects set in. Patient 17: "After the first three treatments, I got infections. I was hospitalised three times in that period. Exercise never really got started" (female, 49, breast cancer).

\section{Rethinking exercise identity and transforming priorities}

The analysis from the postintervention interviews showed: building self-confidence, believing in one's own abilities and having the willpower to reach new goals, representing a shift in focus from work to their own physique. The newly acquired self-discipline was viewed with pride, as an impetus to set and reach new goals.

Patient 13: "I'm really proud of myself. I've changed. Before I got sick I was uninterested in exercise. I took short walks with the dog, worked full time and had my family and other hobbies. I want to keep using my pedometer and plan to walk 10000 steps a day and run a couple times a week" (female, 49, breast cancer). According to the patients, participating in PA improved their physical and emotional well-being, leading them to reflect on prioritising PA in the future. Patient 10: "I am managing engineer and I hadn't exercised for 2 years. I saw the project as a chance to get started. I need a whip over my head. It's necessary when your mind is filled with worry about the future. After doing the programme, my body is much stronger. I'm doing well mentally [and] I have clear objectives for the future. I run $10 \mathrm{~K}$ a week, joined the running club and I want to horseback ride. My disease has led me to reconsider my work situation. Preliminarily I'm working part-time because I have to take better care of myself" (female, 44, breast cancer). Patient 2: "I participated almost $100 \%$ in the exercise programme. I never dreamed being active would have such a good effect on me. My lung function has improved, I can climb stairs and I've halved the number of cigarettes I smoke. I want to continue being physically active at a training club for elderly people" (female, 67, breast cancer).

Patients of working age resumed work when treatment ended, putting their work situations into the forefront. Some patients negotiated to get better work conditions. Patient 14: "I spoke with my employer about how stressful work was as an IT-engineer. I'm convinced that I'll resign if things don't change, so I have time to work out. Now I have fewer responsibilities and will start part-time. My illness has made me see what is important. I have no doubt that exercise improves my wellbeing and now I feel strong enough to work on my terms" (male, 38, colon cancer).

\section{DISCUSSION}

Exploring patients' previous exercise history is a key theme in studies targeting patients with cancer who were inactive prediagnosis because exercise history may affect their attitude towards initiating PA. Participants reported that they transformed their inactive exercise attitude, indicating a shift from being non-exercisers to exercisers, irrespective of pre-exercise history. This shift in PA behaviour was due to the oncologist recommendations, counselling and support from healthcare professionals and due to patient perceptions of the bodily, emotional and social benefits of exercise/PA with peers, family or friends.

Recurring topics in all patient reflections included a lack of self-discipline, motivation and physical laziness but also a stressful work life. Our sample comprised highly educated relatively young patients with cancer with a mean age of 49 , which explained their focus on work conditions and level of stress as a contributing factor in deprioritising exercise. Our findings were consistent with results from a study of 5000 Danish employees, concluding that highly educated employees experienced higher levels of work-related stress than their less educated counterparts. ${ }^{32}$

Young, highly educated patients with cancer represent an at-risk group, which breaks with the notion that only poorly educated patients have an inactive lifestyle. This is the cause for clinicians and exercise teams to pay special attention to them. Studies correlate higher education 


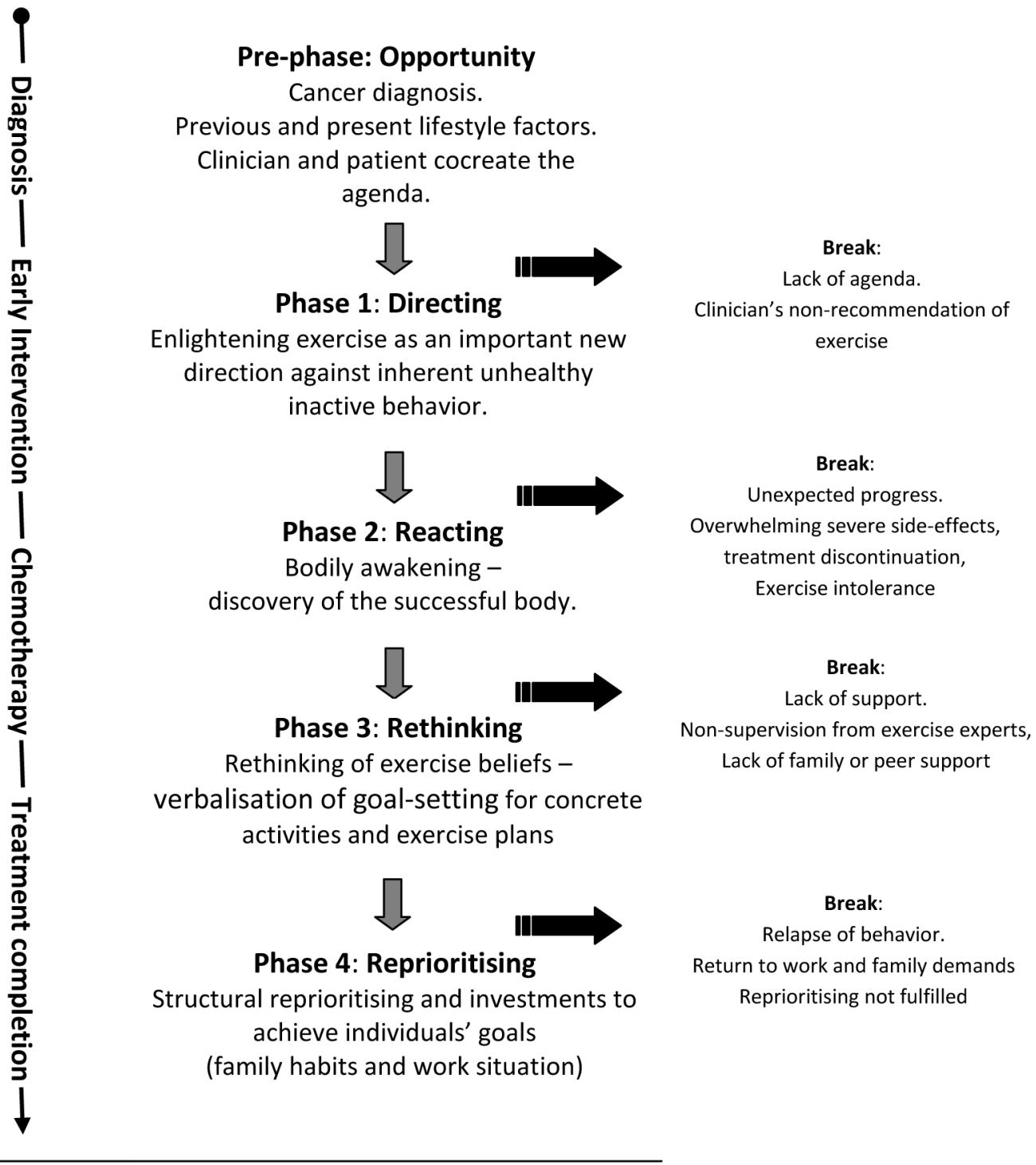

FIGURE 2: Model of the exercise transforming process for physically inactive cancer patients during chemotherapy

Figure 2 Model of the exercise transforming process for physically inactive cancer patients.

level with the likelihood of being physically active ${ }^{33}$ but that a higher education level often means doing sedentary work. ${ }^{34}$ Our study demonstrates that changing work conditions in the knowledge society require focus on detecting and advising 'new' at-risk groups among patients with cancer who differ in age and lifestyle from their respective diagnostic groups.

Participant descriptions depicted a transformative process comprising four phases. Participants generally did not rely on their own physical ability during chemotherapy and looked critically at previous and present lifestyle factors (figure 2, pre-phase: Opportunity). Without exception, every patient said that their oncologist recommended PA, which they found relevant. Other studies on breast, colon and prostate cancer patients show that exercise was only mentioned in the clinic $35 \%$ of the time.$^{35}$ None of our study participants spontaneously began exercising from diagnosis to first chemotherapy consultation, which undermines 'the theory of the diagnosis as the teachable moment'. ${ }^{36}$ The oncologist's perceived authority increased patient awareness about changing their attitude towards PA and ECNS counselling provided important knowledge, both affecting patients' initial steps towards transforming their attitudes towards exercise (figure 2, phase 1: Directing). Patients were enlightened about exercise as an important way to combat physical inactivity and to handle their cancer diagnosis. Our study confirmed that the first chemotherapy consultation represents a window for influence from oncologists and ECNSs. ${ }^{37} 38$

Patients reported a preference for supervised intervention meeting 4 days/week, which was surprising 
considering their previously inactive lifestyle and in contrast to patients' preference for PA walking. ${ }^{39}$ Participants equated this with their lack of self-discipline, their need for supervision and exercising with their peers. Qualitative studies among active, prediagnosis patients with cancer identified similar needs. ${ }^{25}{ }^{40}$ Physically inactive, prediagnosis patients with cancer seemed to overcome the barrier of transportation distance identified in other studies. ${ }^{41}$ Participants emphasised that their level of PA depended on how chemotherapy affected them, with the majority resuming PA after a few days, in accordance with two qualitative studies on physically active, prediagnosis patients undergoing chemotherapy. ${ }^{22}{ }^{42}$ Our findings confirmed that sedentary, prediagnosis patients used the same strategy to manage side effects as physically active ones.

Side effects caused participation in exercise to fluctuate, leading to a failure to practice PA for three hospitalised patients. The majority, however, experienced unexpected bodily benefits and were emboldened by their performance. This discovery of 'the successful body' is a key factor in the second step of the transformation process. (figure 2, phase 2: Reacting). Participants who continued highlighted the emotional benefits, mirroring results from qualitative studies on breast cancer patients' motivations for PA. ${ }^{21} 24{ }^{43}$ Valuable social relationships, of importance to our target group's desire to continue PA, were established in group exercise. Other qualitative group exercise studies targeting patients with cancer identified a similar mechanism. ${ }^{26} 4042$

Participants in the pedometer intervention also experienced social benefits, though of a different nature, as ties with spouses and friends became stronger, encouraging them to stay active. These participants nonetheless also asked to participate in groups with peers, as in a study on women exercising in a home setting. ${ }^{24}$

Our findings show that participants in the 12-week PA interventions experienced a new form of self-discipline, which caused them to rethink their abilities, leading to the third transformation phase, where exercise became a part of their mindset and goals (figure 2, phase 3: Rethinking). The lack of self-discipline patients described at baseline became a belief in their own abilities and the willpower to realise new exercise/PA goals. Despite barriers participants realised their objectives, fostering optimism about maintaining their commitment to exercise/PA by joining teams in sports clubs as the preferred form of exercise. Participants of working age who had previously prioritised work re-examined this when the time to resume working approached. Various strategies emerged during the interviews; some participants negotiating transitional agreements with employers and others seeking temporary reprieves from management responsibilities. Finally, some participants said a job change was necessary to hold onto their own priorities, as a sharper focus on making exercise/PA a habit became a reality. The fourth and final step in the transformation process encompassed a reprioritisation of structural life features, for example, work situation, family and leisure time behaviour (figure 2, phase 4: Reprioritising).

\section{Methodological considerations}

Our study population comprised a group of young, highly educated breast and colon cancer patients compared with the total population of breast and colon cancer patients in Denmark. ${ }^{1}$

The sample demonstrated similarities between the sexes regarding perceptions, preferences, experiences and adherence rates. The young women who participated equalled the men concerning work and family life challenges. Adherence rates (table 2) were 74\% (HIGHHOSP) and $75 \%$ (LOWPED), indicating that the patients had adequate experience to reflect on the underlying mechanisms and shift in attitude and behaviour during their trajectory, which is in accordance with intervention adherence rates for physically active, prediagnosis patients with cancer. ${ }^{344}$ More patients with colon cancer may have saturated a further detailed understanding of what patients experience during their disease trajectory. The patients with colon cancer, who chose to participate in the study may thus represent participants with a particularly positive attitude and readiness to adjust their past lifestyles. However, the literature shows that recruiting patients with colon cancer for PA interventions is difficult. $^{44} 45$

The study was not incorporating in-depth follow-up interviews, which could have contributed valuable knowledge about patients' abilities to maintain PA behaviour. One could argue that the individual patient's unique trajectory from prediagnosis to post intervention would help clarify more specific issues, such as bodily reactions to side effects.

\section{CONCLUSION}

Prediagnosis physically inactive patients with cancer need to be identified at onset of chemotherapy and continuously supported during their treatment by oncologists, nurses and exercise teams to initiate, facilitate and maintain a physically active behaviour. The patients' attitude towards physical activity transformed from having no priorities in patients' daily lives prediagnosis to be highly prioritised during treatment; from failed exercise discipline to continuous participation.

\section{Implication}

This study identified four important phases in the PA transformation process of relevance to clinicians in identifying, motivating and supporting physically inactive patients with cancer at long-term risk. As such, we believe its relevance and transferability have potential for scientific and clinical application. Interventional research that aims to adopt behavioural change towards increased PA could import this model as a guide for interventional activities across various cancer diagnoses. Clinicians should pay attention towards highly educated young 
patients with cancer at onset of adjuvant chemotherapy whom are at specific risk of sedentary lifestyle due to stressful ambitious careers.

Acknowledgements The authors wish to thank all participants involved in this study for sharing their perceptions and experiences of participation during their treatment trajectory.

Contributors LA was responsible for data collection; furthermore, LA was first author and together with CA and TM participated in data analysis, interpretation and writing processes. $\mathrm{CL}$ and $\mathrm{KB}$ had a leading role in the intervention activities. All authors have read and approved the final manuscript.

Funding The present study was conducted by grants from the Center for Integrated Rehabilitation of Cancer patients (CIRE), which was established in 2011 and is supported by the Danish Cancer Society and the Novo Nordisk Foundation. The project has furthermore received grants from TrygFonden Denmark, grant no 7-12-0401.

\section{Competing interests None declared.}

Patient consent Detail has been removed from this case description/these case descriptions to ensure anonymity. The editors and reviewers have seen the detailed information available and are satisfied that the information backs up the case the authors are making.

Ethics approval The Scientific Ethics Committee of the Capital Region of Denmark and the Danish Data Protection Agency.

Provenance and peer review Not commissioned; externally peer reviewed.

Data sharing statement No additional data are available.

Open Access This is an Open Access article distributed in accordance with the Creative Commons Attribution Non Commercial (CC BY-NC 4.0) license, which permits others to distribute, remix, adapt, build upon this work non-commercially, and license their derivative works on different terms, provided the original work is properly cited and the use is non-commercial. See: http://creativecommons.org/ licenses/by-nc/4.0/

(C) Article author(s) (or their employer(s) unless otherwise stated in the text of the article) 2017. All rights reserved. No commercial use is permitted unless otherwise expressly granted.

\section{REFERENCES}

1. The Danish Health Data Authority. Cancer Incidence in Denmark: Danish cancer registry 2015. Copenhagen The Danish Health Data Authority; 2016.

2. Schmitz KH, Courneya KS, Matthews C, et al. American College of Sports Medicine roundtable on exercise guidelines for cancer survivors. Med Sci Sports Exerc 2010;42:1409-26.

3. Mishra SI, Scherer RW, Snyder C, et al. Exercise interventions on health-related quality of life for people with cancer during active treatment. Clin Otolaryngol 2012;37:390-2.

4. Fong DY, Ho JW, Hui BP, et al. Physical activity for cancer survivors: meta-analysis of randomised controlled trials. BMJ 2012;344:e70.

5. Furmaniak AC, Menig M, Markes $\mathrm{MH}$. Exercise for women receiving adjuvant therapy for breast cancer. Cochrane Database Syst Rev 2016;9:CD005001.

6. Holmes MD, Chen WY, Feskanich D, et al. Physical activity and survival after breast cancer diagnosis. JAMA 2005;293:2479-86.

7. Meyerhardt JA, Giovannucci EL, Holmes MD, et al. Physical activity and survival after colorectal cancer diagnosis. J Clin Oncol 2006;24:3527-34.

8. Lee IM, Shiroma EJ, Lobelo F, et al. Effect of physical inactivity on major non-communicable diseases worldwide: an analysis of burden of disease and life expectancy. Lancet 2012;380:219-29.

9. Bourke L, Homer KE, Thaha MA, et al. Interventions for promoting habitual exercise in people living with and beyond cancer. Cochrane Database Syst Rev 2013;9:CD010192.

10. Herman DR, Ganz PA, Petersen L, et al. Obesity and cardiovascular risk factors in younger breast cancer survivors: The Cancer and Menopause Study (CAMS). Breast Cancer Res Treat 2005;93:13-23.

11. Jones LW, Haykowsky MJ, Swartz JJ, et al. Early breast cancer therapy and cardiovascular injury. J Am Coll Cardiol 2007;50:1435-41.

12. Hawkes AL, Lynch BM, Owen N, et al. Lifestyle factors associated concurrently and prospectively with co-morbid cardiovascular disease in a population-based cohort of colorectal cancer survivors. Eur J Cancer 2011;47:267-76.

13. Berterö C, Chamberlain Wilmoth M. Breast cancer diagnosis and its treatment affecting the self: a meta-synthesis. Cancer Nurs 2007;30:194-202.

14. Oh HS, Seo WS. Systematic review and meta-analysis of the correlates of cancer-related fatigue. Worldviews Evid Based Nurs 2011;8:191-201.

15. Courneya KS, Friedenreich CM. Relationship between exercise pattern across the cancer experience and current quality of life in colorectal cancer survivors. J Altern Complement Med 1997:3:215-26.

16. Schmidt ME, Wiskemann J, Ulrich CM, et al. Self-reported physical activity behavior of breast cancer survivors during and after adjuvant therapy: 12 months follow-up of two randomized exercise intervention trials. Acta Oncol 2017;56:618-27.

17. WHO. Global recommendations on physical activity for health Geneva: World Health Organization, 2010.

18. DHMA. Physical activity: recommendations for adults (18-64 years old). Copenhagen Danish Health and Medicines Authority; 2014. http://www.sst.dk/English/Health_promotion/Physical_activity/ Recommendations for adults.aspx (accessed May 6 2015)

19. Bourke L, Homer KE, Thaha MA, et al. Interventions to improve exercise behaviour in sedentary people living with and beyond cancer: a systematic review. Br J Cancer 2014;110:831-41.

20. Moustsen IR, Larsen SB, Vibe-Petersen J, et al. Social position and referral to rehabilitation among cancer patients. Acta Oncol 2015;54:720-6.

21. Emslie C, Whyte F, Campbell A, et al. 'I wouldn't have been interested in just sitting round a table talking about cancer'; exploring the experiences of women with breast cancer in a group exercise trial. Health Educ Res 2007;22:827-38.

22. Ingram C, Wessel J, Courneya KS. Women's perceptions of homebased exercise performed during adjuvant chemotherapy for breast cancer. Eur J Oncol Nurs 2010;14:238-43.

23. Swenson KK, Nissen MJ, Henly SJ. Physical activity in women receiving chemotherapy for breast cancer: adherence to a walking intervention. Oncol Nurs Forum 2010;37:321-30.

24. Husebø AM, Karlsen B, Allan $\mathrm{H}$, et al. Factors perceived to influence exercise adherence in women with breast cancer participating in an exercise programme during adjuvant chemotherapy: a focus group study. J Clin Nurs 2015;24(3-4):500-10.

25. Midtgaard J, Hammer NM, Andersen C, et al. Cancer survivors experience of exercise-based cancer rehabilitation - a metasynthesis of qualitative research. Acta Oncol 2015;54:609-17.

26. Browall M, Mijwel S, Rundqvist $\mathrm{H}$, et al. Physical activity during and after adjuvant treatment for breast cancer. Integr Cancer Ther 2016 (Epub ahead of print).

27. Henriksson A, Arving C, Johansson B, et al. Perceived barriers to and facilitators of being physically active during adjuvant cancer treatment. Patient Educ Couns 2016;99:1220-6.

28. Smith JA, Flowers P, Larkin M. Interpretative phenomenological analysis: theory, method and research. Los Angeles: SAGE, 2009.

29. Tong A, Sainsbury P, Craig J. Consolidated criteria for reporting qualitative research (COREQ): a 32-item checklist for interviews and focus groups. Int J Qual Health Care 2007;19:349-57.

30. Møller T, Lillelund C, Andersen C, et al. At cancer diagnosis: a 'window of opportunity' for behavioural change towards physical activity. A randomised feasibility study in patients with colon and breast cancer. BMJ Open 2013;3:e003556.

31. Møller T, Lillelund C, Andersen C, et al. The challenge of preserving cardiorespiratory fitness in physically inactive patients with colon or breast cancer during adjuvant chemotherapy: a randomised feasibility study. BMJ Open Sport Exerc Med 2015;1:1-14.

32. Clausen T, Christensen KB, Borg V. Positive work-related states and long-term sickness absence: a study of register-based outcomes. Scand J Public Health 2010;38(3 Suppl):51-8.

33. Flachs EM, Eriksen L, Koch MB, et al. The burden of disease in Denmark: diseases Vol. 382. Copenhagen: Danish Health Authority, 2015.

34. Ekholm O, Kjøller M, Davidsen M, et al. Health and morbidity in Denmark - development since 1987 Vol. 307. Copenhagen: National Institute of Public Health, 2006.

35. Nyrop KA, Deal AM, Williams GR, et al. Physical activity communication between oncology providers and patients with early-stage breast, colon, or prostate cancer. Cancer 2016;122:470-6.

36. Demark-Wahnefried W, Aziz NM, Rowland JH, et al. Riding the crest of the teachable moment: promoting long-term health after the diagnosis of cancer. J Clin Oncol 2005;23:5814-30. 
37. McBride CM, Emmons KM, Lipkus IM. Understanding the potential of teachable moments: the case of smoking cessation. Health Educ Res 2003;18:156-70.

38. Park JH, Lee J, Oh M, et al. The effect of oncologists' exercise recommendations on the level of exercise and quality of life in survivors of breast and colorectal cancer: a randomized controlled trial. Cancer 2015;121:2740-8.

39. Bernardo LM, Abt KL, Ren D, et al. Self-reported exercise during breast cancer treatment: results of a national survey. Cancer Nurs 2010;33:304-9.

40. Adamsen L, Andersen C, Midtgaard J, et al. Struggling with cancer and treatment: young athletes recapture body control and identity through exercise: qualitative findings from a supervised group exercise program in cancer patients of mixed gender undergoing chemotherapy. Scand J Med Sci Sports 2009;19:55-66.

41. Rogers LQ, Courneya KS, Verhulst S, et al. Factors associated with exercise counseling and program preferences among breast cancer survivors. J Phys Act Health 2008;5:688-705.
42. Andersen C, Rørth M, Ejlertsen B, et al. Exercise despite pain-breast cancer patient experiences of muscle and joint pain during adjuvant chemotherapy and concurrent participation in an exercise intervention. Eur J Cancer Care 2014;23:653-67.

43. Bulmer SM, Howell J, Ackerman L, et al. Women's perceived benefits of exercise during and after breast cancer treatment. Women Health 2012;52:771-87.

44. Shang J, Wenzel J, Krumm S, et al. Who will drop out and who will drop in: exercise adherence in a randomized clinical trial among patients receiving active cancer treatment. Cancer Nurs 2012;35:312-22.

45. van Waart $\mathrm{H}$, Stuiver MM, van Harten WH, et al. Effect of low-intensity physical activity and moderate- to high-intensity physical exercise during adjuvant chemotherapy on physical fitness, fatigue, and chemotherapy completion rates: results of the PACES randomized clinical trial. J Clin Oncol 2015; 33:1918-27. 